\title{
Nickel-catalyzed direct synthesis of dialkoxymethane ethers ${ }^{\dagger}$
}

\author{
MURUGAN SUBARAMANIAN ${ }^{\mathrm{a}}$, ABHIJIT BERA $^{\mathrm{b}}$, BHAGAVATULA L V PRASAD $^{\mathrm{b}, *}$ (1) \\ and EKAMBARAM BALARAMAN ${ }^{\mathrm{a}, * \text { (D) }}$ \\ ${ }^{a}$ Catalysis Division, CSIR-National Chemical Laboratory (CSIR-NCL), Dr. Homi Bhabha Road, Pune, \\ Maharashtra 411 008, India \\ bPhysical and Material Chemistry Division, CSIR-National Chemical Laboratory (CSIR-NCL), Dr. Homi \\ Bhabha Road, Pune, Maharashtra 411 008, India \\ E-mail: pl.bhagavatula@ncl.res.in; eb.raman@ncl.res.in
}

MS received 16 May 2017; revised 4 July 2017; accepted 5 July 2017

\begin{abstract}
A simple and efficient method for the preparation of dialkoxymethane ethers (oxymethylene ethers) from alcohols and paraformaldehyde in the presence of commercially available nickel(II) salt is described. The reaction proceeds readily under neutral, solvent-free conditions using paraformaldehyde as a $\mathrm{C}_{1}$ source. The present strategy has a broad substrate scope including aliphatic (both primary and secondary) and aromatic alcohols and provides a benign method for the preparation of symmetrical dialkoxymethanes in good yields (up to $89 \%$ ).
\end{abstract}

Keywords. Nickel catalysis; alcohol; paraformaldehyde; ether; solvent-free condition.

\section{Introduction}

Ethers constitute the most diverse family of organic compounds and are ubiquitous in many natural products and pharmaceuticals. ${ }^{1}$ The extent to which they can be utilized as an organic intermediate in contemporary science depends on the selectivity and efficiency of the processes for their preparation from simple feedstock chemicals. Consequently, there are various synthetic routes that have been documented to access symmetrical as well as unsymmetrical ethers, ranging from the classical Williamson ether synthesis ${ }^{2}$ to recent transition-metal catalyzed cross-coupling reactions employing alcohols. ${ }^{3}$

In recent years, the dialkoxymethane (oxymethylene ether) has been gaining increasing interest because of its advantageous properties as fuel additives for combustion engines (e.g., dimethoxymethane, DMM). ${ }^{4}$ Further various biologically significant compounds, for example, Miloxacin (antibacterial agent) ${ }^{5}$ and Cephalotaxine (antiviral and antitumor agent) ${ }^{6}$ contain the dialkoxymethane motif. The dialkoxymethane and its derivatives have been used as a source for the synthesis of plasticizers, and monomers for cross-linking agents. ${ }^{7}$ In addition, they have been used as an intermediate for the preparation of drug-related compounds such as anti-HIV-1 drug (TNK-651) ${ }^{8}$ microbicidally active drug (YML-220) for infected MT-4 cells, ${ }^{9}$ portmanteau inhibitors against reverse transcriptase (RT), and the inhibitor of HIV-1 Integrase (IN), etc. ${ }^{10,11}$ The use of dialkoxymethane as reagents for the $\mathrm{N}$ alkoxymethylation of secondary amides in the presence of Lewis acids ${ }^{12}$ and Brønsted acids ${ }^{13}$ has also been reported. Given their importance, the development of efficient, benign strategies for the synthesis of dialkoxymethane is a central research area in synthetic chemistry (Figure 1).

The general strategy for the preparation of dialkoxymethanes involves the condensation reaction of toxic formaldehyde with alcohols under acidic conditions. ${ }^{9,14,15}$ Several methods including $\mathrm{NaH} /$ dibro momethane, ${ }^{9}$ montmorillonite/dichloromethane in $\mathrm{NaOH} / \mathrm{H}_{2} \mathrm{O}$ mixture, ${ }^{14 \mathrm{c}} \mathrm{Me}_{3} \mathrm{SiC} 1 / \mathrm{Me}_{2} \mathrm{SO}^{14 \mathrm{a}}$ with alcohol have been reported. The $\mathrm{Cu}-\mathrm{NHC}$-catalyzed

\footnotetext{
*For correspondence

$\dagger$ Dedicated to Professor K. C. Kumara Swamy on the occasion of his 60th birth anniversary.
}

Electronic supplementary material: The online version of this article (doi:10.1007/s12039-017-1339-6) contains supplementary material, which is available to authorized users. 


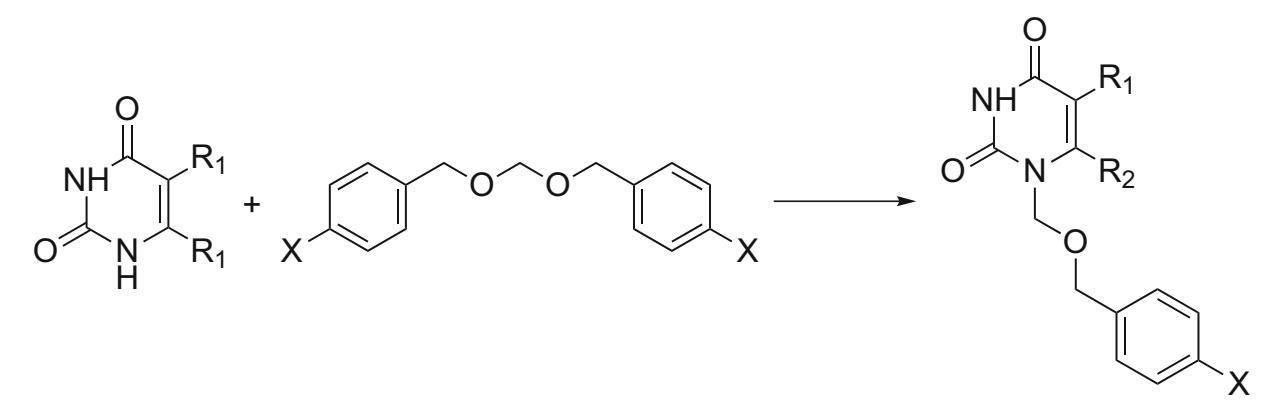<smiles>CC(C)c1c(Cc2ccccc2)n(COCc2ccccc2)c(=O)[nH]c1=O</smiles>

Anti HIV-1 drug (TNK-651)<smiles>CC(C)c1c(Cc2ccccc2)n(COCc2ccc(C(=O)/C=C(\O)C(=O)O)cc2)c(=O)[nH]c1=O</smiles>

Portmanteau inhibitors against Reverse Transcriptase (RT) and Integrase (IN)<smiles>CCc1c(C(F)c2cc(C)cc(C)c2)n(COCc2ccc(C#CCO)cc2)c(=O)[nH]c1=O</smiles>

Microbicidal active drug for MT-4 cells (YML-220)<smiles>CC(C)c1c(Cc2ccccc2)n(COCc2ccc(F)cc2)c(=O)n(O)c1=O</smiles>

Inhibitor of HIV-1 Integrase (IN)

Figure 1. Dialkoxymethane as intermediates in the synthesis of drug-related molecules.

preparation of dialkoxymethanes from dichloromethane with alcohols has been reported by Zhan et al. ${ }^{14 \mathrm{j}}$ A heterogeneous Kaolinite (a clay mineral of alumina and silica) catalyzed preparation of dialkoxymethanes using paraformaldehyde has also been reported; however, it requires high temperature and a long reaction time. ${ }^{14 \mathrm{e}}$ Very recently, Klankermayer et al., demonstrated the catalytic conversion of $\mathrm{CO}_{2}\left(20\right.$ bar) and $\mathrm{H}_{2}$ (60 bar) in the presence of alcohols into dialkoxymethane ethers in a multistep reaction using a well-defined ruthenium-triphos catalyst and aluminium triflate as a Lewis acidic co-catalyst. The achieved turnover numbers were about 200 TONs for methanol and varied from 50 to 120 TONs for the higher aliphatic alcohols. ${ }^{16}$ However, most of these methods suffer from several disadvantages such as (i) the use of a stoichiometric amount of hazardous halogenated reagents resulting in copious waste, (ii) operate under acidic or basic conditions and elevated reaction temperature $\left(\sim 120^{\circ} \mathrm{C}\right)$, (iii) require longer reaction times, and (iv) often take place in harmful organic solvents. ${ }^{14}$ Hence, it would be appealing to develop a mild and environmentally benign synthesis of dialkoxymethane ethers under neutral conditions and to avoid the use of toxic organic solvents. Here, we report a simple, efficient method for the preparation of dialkoxymethanes from alcohols and paraformaldehyde (which is cheap and stable at ambient conditions as well as exhibits lowtoxicity; for selected examples of paraformaldehyde used as a C-1 source), ${ }^{17}$ in the presence of a commercially available nickel(II) salt. The reaction proceeds readily under mild, neutral and solvent-free conditions in a short period of reaction time. To the best of our knowledge, there are no reports that describe 


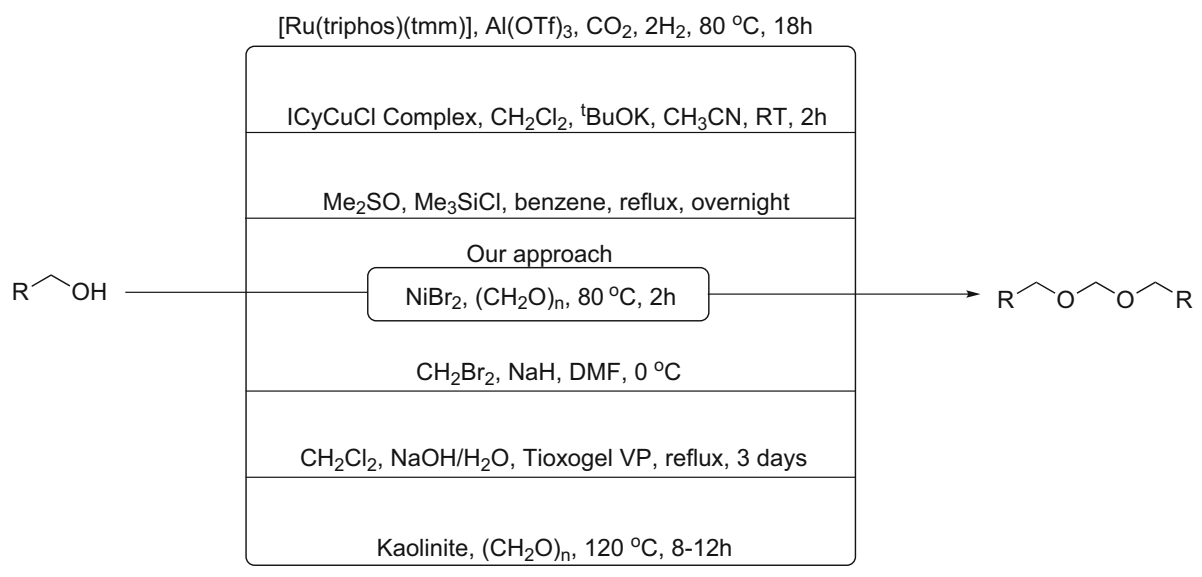

Scheme 1. Various strategies for the preparation of dialkoxymethanes.

the nickel-catalyzed synthesis of dialkoxymethanes (Scheme 1).

\section{Experimental}

\subsection{Materials and methods}

All catalytic experiments were carried out using standard Schlenk techniques. The reagents and solvents used were chemically pure and analytical grade, and the solvents were dried according to standard procedures. Alcohols were distilled under vacuum. Nickel salts (purchased from SigmaAldrich) and paraformaldehyde were used without additional purification. Column chromatography was performed with $\mathrm{SiO}_{2}$ (Silicycle Siliaflash F60 (230-400 mesh)). ${ }^{1} \mathrm{H}$ NMR $(200,400$ or $500 \mathrm{MHz}),{ }^{13} \mathrm{C}\{1 \mathrm{H}\} \mathrm{NMR}(50$ or $100 \mathrm{MHz})$ spectra were recorded on the NMR spectrometer. Deuterated chloroform was used as the solvent, and chemical shift values $(\delta)$ are reported in parts per million relative to the residual signals of this solvent $\left[\delta 7.26\right.$ for ${ }^{1} \mathrm{H}$ (chloroform-d), $\delta 77.2$ for ${ }^{13} \mathrm{C}\{1 \mathrm{H}\}$ (chloroform-d). Abbreviations used in the NMR follow-up experiments are as follows: br, broad; s, singlet; d, doublet; t, triplet; q, quartet; $\mathrm{m}$, multiplet. GC analysis was carried out using an HP- 5 column ( $30 \mathrm{~m}, 0.25 \mathrm{~mm}, 0.25 \mu \mathrm{m})$. Mass spectra were obtained on a GCMS-QP 5000 instruments with ionization voltages of $70 \mathrm{eV}$. High-resolution mass spectra (HRMS) were obtained by fast atom bombardment (FAB) using a double focusing magnetic sector mass spectrometer and electron impact (EI) ionization technique (magnetic sector-electric sector double focusing mass analyzer).

\subsection{Synthesis of Ni-Octane thiolate}

To $500 \mathrm{mg}$ of nickel(II) acetylacetonate (or nickel(II)acetate) taken in an eppendorf tube of $2 \mathrm{~mL}$ capacity, $900 \mu \mathrm{L}$ of octanethiol was added and the tube was shaken vigorously. The reaction mixture turned black instantaneously. The mixture was washed thoroughly with ethanol, and the black product was air-dried at room temperature. The obtained black powder goes readily into organic solvents such as chloroform, toluene, $\mathrm{CCl}_{4}$, etc. The powder was characterized using PXRD and TEM analysis and the data is consistent with the literature compound. ${ }^{18}$

\subsection{Synthesis of $\mathrm{Ni}_{3} \mathrm{~S}_{2}$ Sheets}

Nickel octanethiolate powder sample was heated in a tubefurnace equipped with Argon gas flow maintaining a constant temperature of $750^{\circ} \mathrm{C}$ and at a constant gas flow rate of 2 $\mathrm{mL} / \mathrm{sec}$ for $6 \mathrm{~h}$. After heating for $6 \mathrm{~h}$, the sample was cooled to room temperature and the final product was collected and characterized by PXRD and TEM (see Supporting Information).

\subsection{General procedure for the preparation of dialkoxymethane ethers from alcohols}

In an oven-dried screw cap reaction tube $(15 \mathrm{~mL})$, alcohol $(0.5$ $\mathrm{mmol})$, paraformaldehyde (1 mmol) and $\mathrm{NiBr}_{2}(5 \mathrm{~mol} \%)$ were added under a gentle stream of argon. The reaction mixture was stirred at $80^{\circ} \mathrm{C}$ in an oil bath for $2 \mathrm{~h}$. After completion of the reaction, the mixture was allowed to cool at room temperature, and the reaction was subsequently quenched with water $(10 \mathrm{~mL})$ followed by the extraction with ethyl acetate $(3 \times 10 \mathrm{~mL})$. The organic layer was separated and dried over anhydrous $\mathrm{Na}_{2} \mathrm{SO}_{4}$. Evaporation of the solvent under reduced pressure gave the crude product, which was chromatographed on silica gel using pet. ether and EtOAc (98:2) as an eluent to afford the desired dialkoxymethanes. All the compounds were completely characterized, and the spectroscopic data with copies of spectra are provided in the Supporting Information.

\subsection{Homogeneity test}

An alcohol (0.5 mmol), paraformaldehyde (1 mmol), $\mathrm{NiBr}_{2}$ ( $5 \mathrm{~mol} \%$ ), and one drop of mercury were taken in a roundbottom flask and stirred at $80^{\circ} \mathrm{C}$ temperature. After $2 \mathrm{~h}$, the reaction mixture was allowed to cool to room temperature. The reaction products were analyzed with gas chromatography using $m$-xylene as an internal standard, and the product were confirmed by GC-MS. 
Table 1. Optimization condition for the synthesis of dialkoxymethanes ${ }^{\mathrm{a}}$.

\begin{tabular}{|c|c|c|c|c|}
\hline & $2 \mathrm{Ph} \widehat{1 \mathrm{a}}$ & $\begin{array}{c}\text { cat. [Ni] } \\
\stackrel{\text { Paraformaldehyde }}{\triangle \text { Ar atm }}\end{array}$ & $\widehat{2 a}_{\mathrm{O}} \widehat{\mathrm{Ph}}+\mathrm{H}_{2} \mathrm{O}$ & \\
\hline Entry & Nickel catalyst & Solvent & Temp $\left({ }^{\circ} \mathrm{C}\right)$ & Yield of $\mathbf{2 a}(\%)^{\mathrm{b}}$ \\
\hline 1 & Ni-Octane thiolate & - & $80^{\circ} \mathrm{C}$ & 41 \\
\hline 2 & $\mathrm{Ni}_{3} \mathrm{~S}_{2}$ nano-sheet & - & $80^{\circ} \mathrm{C}$ & 14 \\
\hline 3 & $\mathrm{NiBr}_{2}$ & - & $80^{\circ} \mathrm{C}$ & $80(71)^{c}$ \\
\hline 4 & $\mathrm{NiBr}_{2}+\mathrm{DPPE}$ & - & $80^{\circ} \mathrm{C}$ & 24 \\
\hline 5 & $\mathrm{NiBr}_{2}+\mathrm{BPy}$ & - & $80^{\circ} \mathrm{C}$ & 11 \\
\hline 6 & $\mathrm{NiBr}_{2}+$ Pyridine & - & $80^{\circ} \mathrm{C}$ & Trace \\
\hline 7 & - & - & $80^{\circ} \mathrm{C}$ & n.d \\
\hline 8 & $\mathrm{NiCl}_{2}$ & - & $80^{\circ} \mathrm{C}$ & $67^{\mathrm{b}}$ \\
\hline 9 & $\mathrm{Ni}(\text { acac })_{2}$ & - & $80^{\circ} \mathrm{C}$ & n.d \\
\hline 10 & $\mathrm{NiCp}_{2}$ & - & $80^{\circ} \mathrm{C}$ & n.d \\
\hline 11 & $\mathrm{Ni}(\mathrm{OAc})_{2}$ & - & $80^{\circ} \mathrm{C}$ & 23 \\
\hline 12 & $\mathrm{Ni}\left[\mathrm{PPh}_{3}\right]_{4}$ & - & $80^{\circ} \mathrm{C}$ & n.d \\
\hline 13 & $\mathrm{NiBr}_{2}$ & Toluene & $80^{\circ} \mathrm{C}$ & n.d \\
\hline 14 & $\mathrm{NiBr}_{2}$ & Acetonitrile & $80^{\circ} \mathrm{C}$ & Trace \\
\hline 15 & $\mathrm{NiBr}_{2}$ & THF & $80^{\circ} \mathrm{C}$ & Trace \\
\hline 16 & $\mathrm{NiBr}_{2}$ & - & $\mathrm{rt}$ & n.d \\
\hline 17 & $\mathrm{NiBr}_{2}$ & - & $50^{\circ} \mathrm{C}$ & 26 \\
\hline 18 & $\mathrm{NiBr}_{2}$ & - & $110^{\circ} \mathrm{C}$ & 67 \\
\hline 19 & $\mathrm{NiBr}_{2}+\mathrm{Hg}$ & - & $80^{\circ} \mathrm{C}$ & 70 \\
\hline
\end{tabular}

${ }^{a}$ Reaction condition: Benzyl alcohol $1 \mathbf{a}(0.5 \mathrm{mmol}),(\mathrm{HCHO})_{\mathrm{n}}(1.0 \mathrm{mmol})$, cat.[Ni] $(5 \mathrm{~mol} \%)$, heated at $80^{\circ} \mathrm{C}$ in an oil bath for $2 \mathrm{~h}$ under argon atm (entries 3-19).

${ }^{b}$ Yields were determined by GC using $m$-xylene as an internal standard.

${ }^{\mathrm{c}}$ Isolated yields. $n . d$ not detected.

\section{Results and Discussion}

Nickel based catalysts have gained significant attention in sustainable chemical synthesis owing to the Nickel abundance, economical and versatile reactivity. ${ }^{19}$ Optimization studies on the nickel-catalyzed direct synthesis of dialkoxymethane ethers are summarized in Table 1. Initially, the catalytic activity of Ni-Octane thiolate was tested using benzyl alcohol (1a) as a model substrate and paraformaldehyde as a $\mathrm{C}-1$ source. Thus, treatment of benzyl alcohol $(0.5 \mathrm{mmol})$ with paraformaldehyde $(1 \mathrm{mmol})$ at $80^{\circ} \mathrm{C}$ for $8 \mathrm{~h}$ with a catalytic amount of Ni-Octane thiolate under solvent-free conditions, resulted in $41 \%$ of bis(benzyloxy)methane 2a (Table 1, entry 1). Under identical conditions $\mathrm{Ni}_{3} \mathrm{~S}_{2}$ nano-sheets (after pyrolysis of Ni-Octane thiolate at $750^{\circ} \mathrm{C}$ ) gave only $14 \%$ of the desired product (Table 1 , entry 2). Encouraged by these preliminary results, next we have examined several nickel catalysts for this transformation. Notably, with $\mathrm{NiBr}_{2}(5 \mathrm{~mol} \%)$, the reaction of benzyl alcohol with paraformaldehyde at $80^{\circ} \mathrm{C}$ in an oil bath for $2 \mathrm{~h}$ resulted $71 \%$ isolated yield of $2 \mathrm{a}$ (Table 1, entry 3). Next, the activity of in situ generated nickel complexes $\left(\mathrm{L}_{\mathrm{n}} \mathrm{Ni}\right)$ was studied. In this regard, a series of monodentate $\left(\mathrm{PPh}_{3}\right.$ and $\left.(o \text {-Tolyl })_{3} \mathrm{P}\right)$ and bidentate ligands (phosphine and nitrogen-based ligands) were tested using nickel(II) bromide as the catalyst precursor (Table 1, entries 4-6). However, almost all of the ligands we examined gave quite low catalytic activity with less than $25 \%$ yield of the desired product 2a. Next, we have investigated the impact of key reaction parameters for the desired transformation. The effect of different nickel catalyst precursors was also explored, and other nickel(II) and nickel(0) catalysts showed less reactivity under regular conditions (Table 1, entries 8-12). Using $2 \mathrm{~mol} \%$ of $\mathrm{NiBr}_{2}$ under the regular conditions, 2a was obtained in $65 \%$ yield and no reaction was observed in the absence of nickel(II) bromide (Table 1, entry 7). The solvent dependency of the same reaction was carried out (Table 1, entries 13-15). Notably, an excess of paraformaldehyde inhibited this transformation. Thus, using 5 eq. of paraformaldehyde under optimized reaction conditions gave only $21 \%$ of $\mathbf{2 a}$. By lowering the temperature, we obtained the product in lower yield (Table 1, entries 16-18) and formation of $\mathbf{2 a}$ was not observed at room temperature. An increase of the reaction time did not increase the yield of the product significantly. Indeed, the mercury poisoning experiment indicates the homogeneous nature of the present nickel catalysis systems (Table 1, entry 19). Gratifyingly, these 
Table 2. Nickel-catalyzed synthesis of dialkoxymethanes: scope of alcohols ${ }^{\mathrm{a}}$.

$$
2 \mathrm{R}_{1} \mathrm{OH} \stackrel{\substack{\left(\mathrm{CH}_{2} \mathrm{O}\right)_{\mathrm{n}} \\ 80^{\circ} \mathrm{C}, 2 \mathrm{~h}, \mathrm{Ar}}}{\stackrel{\mathrm{NiBr}_{2}(5 \mathrm{~mol} \%)}{\longrightarrow}} \mathrm{R} \widehat{\mathrm{O}}_{2} \widehat{\mathrm{O}}_{\mathrm{R}}+\mathrm{H}_{2} \mathrm{O}
$$

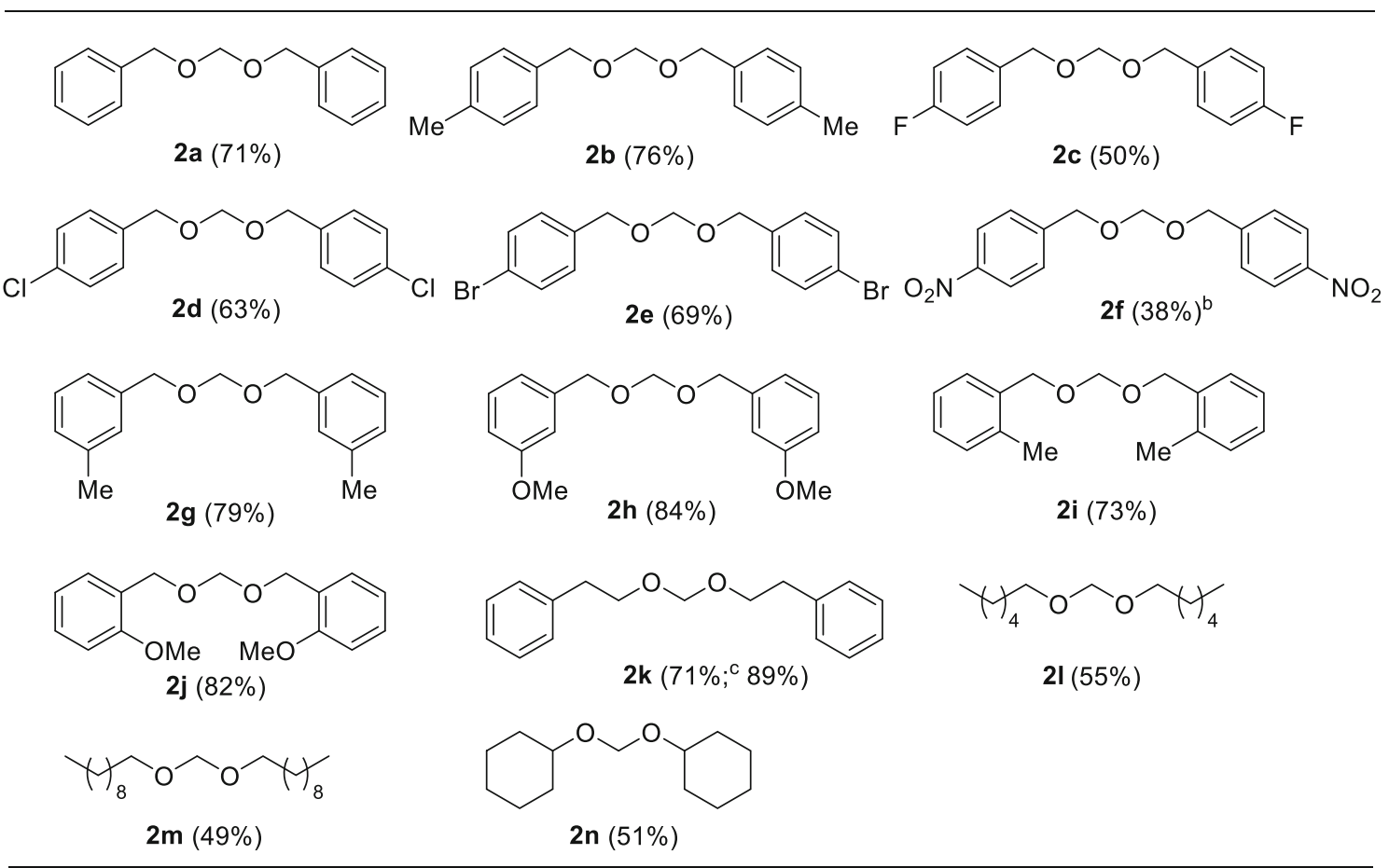

${ }^{a}$ Reaction condition: Alcohol $1(0.5 \mathrm{mmol}),(\mathrm{HCHO})_{\mathrm{n}}(1.0 \mathrm{mmol}), \mathrm{NiBr}_{2}(5 \mathrm{~mol} \%)$, heated at $80^{\circ} \mathrm{C}$ in an oil bath for $2 \mathrm{~h}$; isolated yields are given in the parenthesis.

${ }^{\mathrm{b}}$ Based on GC analysis using $m$-xylene as an internal standard.

c 2 mol\% of $\mathrm{NiBr}_{2}$.

optimal conditions employed a readily available nickel catalyst and paraformaldehyde as $\mathrm{C} 1$-source and proceeded readily at a moderate temperature under neutral conditions with the generation of water as the sole byproduct. Indeed, the solvent-free condition was regarded as the best for the cost and ecological benefits. This representative transformation helps to manifest the practical value that this method may offer for rapid and reliable access of dialkoxymethanes under very mild, eco-benign conditions.

With an optimized the catalytic system in hand (Table 1), next, we have studied the versatility of this new approach towards the synthesis of dialkoxymethanes. As shown in Table 2, the developed strategy is general and compatible with various alcohols including aliphatic (both primary and secondary) and aromatic alcohols and provides a benign method for the preparation of symmetrical dialkoxymethanes in good yields with a shorter reaction time. In general, benzyl alcohol containing no substituents and electron-donating substituents were found to proceed with higher yields than those with electron-withdrawing substituents $\left(-\mathrm{NO}_{2}\right.$ and
-F) under optimized reaction conditions. The reason would be that in presence of an electron-donating group like methoxy at ortho and para positions increases the electron density and thus facilitates the insertion reaction with the nickel complex. Indeed, reactions with various ortho-, meta-, and para-substituted benzyl alcohols proceeded smoothly under our optimized conditions and gave the desired product in moderate to good yields. Aliphatic primary and alicyclic secondary alcohols were also well tolerated for this transformation and gave the desired products in moderate yields (product $\mathbf{2 l}$ in $55 \%, \mathbf{2 m}$ in $49 \%$ and $\mathbf{2 n}$ in $51 \%$ isolated yields).

\section{Conclusions}

In conclusion, a facile nickel-catalyzed synthesis of dialkoxymethanes under neutral conditions is reported using cheap, commercially available $\mathrm{NiBr}_{2}$. Employing this readily available nickel catalyst and paraformaldehyde as C1-source, a variety of alcohols with wide 
substrate scope (aliphatic primary and secondary, and aromatic alcohols) were efficiently converted into dialkoxymethanes in moderate to good yields (up to 89\%) under benign conditions. Solvent-free conditions, moderate temperature, shorter reaction times, and economic viability of the catalyst are the key features of the present protocol.

\section{Supplementary Information (SI)}

Full characterization details, copies of NMR $\left({ }^{1} \mathrm{H}\right.$ and ${ }^{13} \mathrm{C}$ NMR) spectra, HRMS data for all the compounds are presented in Supplementary Information, which is available at www.ias.ac.in/chemsci.

\section{Acknowledgements}

This research was supported by the SERB (SB/FT/CS065/2013). MS and AB thank UGC, India for the research fellowships. BLVP acknowledges the Council of Scientific and Industrial Research, India for the financial support through the project CSC0134.

\section{References}

1. (a) Kubo K, Kohara Y, Imamiya E, Sugiura Y, Inada Y, Furukawa Y, Nishikawa K and Naka T 1993 Nonpeptide Angiotensin II Receptor Antagonists. Synthesis and Biological Activity of Benzimidazolecarboxylic acids $J$. Med. Chem. 36 2182; (b) Ohkawa S, Fukatsu K, Miki S, Hashimoto T, Sakamoto J, Doi T, Nagai Y and Aono T 1997 5-Aminocoumarans: Dual Inhibitors of Lipid Peroxidation and Dopamine Release with Protective Effects Against Central Nervous System Trauma and Ischemia J. Med. Chem. 40 559; (c) Esteki M and Khayamian T 2008 Mechanistic-based Descriptors for QSAR Study of Psychotropic Drug Toxicity Chem. Biol. Drug Des. 72 409

2. (a) March J 1992 In Advanced Organic Chemistry, Reactions, Mechanisms and Structure (New York: John Wiley) p. 386; (b) Mandal S, Mandal S, Ghosh S K, Sar P, Ghosh A, Saha R and Saha B 2016 A Review on the Advancement of Ether Synthesis from Organic Solvent to Water RSC Adv. 669605

3. (a) Hartwig J F 1998 Carbon-Heteroatom Bond-Forming Reductive Eliminations of Amines, Ethers, and Sulfides Acc. Chem. Res. 31 852; (b) Hartwig J F 1998 Transition Metal Catalyzed Synthesis of Arylamines and Aryl Ethers from Aryl Halides and Triflates: Scope and Mechanism Angew. Chem. Int. Ed. 37 2046; (c) Ley S V and Thomas A W 2003 Modern Synthetic Methods for Copper-Mediated C(aryl)[bond]O, C(aryl)[bond]N, and C(aryl)[bond]S Bond Formation Angew. Chem. Int. Ed. 42 5400; (d) Shintou T and Mukaiyama T 2004 Efficient Methods for the Preparation of Alkyl-Aryl and Symmetrical or Unsymmetrical Dialkyl Ethers between Alcohols and Phenols or Two Alcohols by OxidationReduction Condensation J. Am. Chem. Soc. 126 7359; (e) Liu B and Shi B.-F 2015 Transition-Metal-Catalyzed
Etherification of Unactivated C-H Bonds Tetrahedron Lett. 5615 references cited therein

4. (a) Burger J, Siegert M, Strçfer E and Hasse H 2010 Poly(Oxymethylene) Dimethyl Ethers as Components of Tailored Diesel Fuel: Properties, Synthesis and Purification Concepts Fuel 89 3315; (b) Burger J, Strçfer E and Hasse H 2013 Production Process for Diesel Fuel Components Poly(Oxymethylene) Dimethyl Ethers from Methane-based Products by Hierarchical Optimization with Varying Model Depth Chem. Eng. Res. Des. 912648

5. Agui H, Mitani T, Izawa A, Komatsu $T$ and Nakagome T 1977 Studies on Quinoline Derivatives and Related Compounds. 5. Synthesis and Antimicrobial Activity of Novel 1-Alkoxy-1,4-dihydro-4-oxo-3quinolinecarboxylic Acids J. Med. Chem. 20791

6. Paudler W W, Kerley G I and McKay J 1963 The Alkaloids of Cephalotaxus Drupacea and Cephalotaxus Fortune J. Org. Chem. 28 2194; (b) Gouthami P, Chegondi $\mathrm{R}$ and Chandrasekhar S 2016 Formal Total Synthesis of $( \pm)$-Cephalotaxine and Congeners via Aryne Insertion Reaction Org. Lett. 182044

7. Kulkarni M G, Davawala S I, Doke A K and Doke A V 2003 A Novel Synthesis of Diallyloxymethanes Indian J. Chem. 42B 2121

8. Hopkins A L, Ren J, Esnouf R M, Willcox B E, Jones EY, Ross C, Miyasaka T, Walker R T, Tanaka H, Stammers D K and Stuart D I 1996 Complexes of HIV-1 Reverse Transcriptase with Inhibitors of the HEPT Series Reveal Conformational Changes Relevant to the Design of Potent Non-Nucleoside Inhibitors J. Med. Chem. 39 1589

9. Loksha Y M, Pedersen E B, Loddo R, Sanna G, Collu G, Giliberti G and Colla P L Synthesis of Novel Fluoro Analogues of MKC442 as Microbicides Med. Chem. 57 5169

10. Wang Z, Bennett E M, Wilson D J, Salomon C and Vince R 2007 Rationally Designed Dual Inhibitors of HIV Reverse Transcriptase and Integrase J. Med. Chem. 50 3416

11. Tang J, Maddali K, Metifiot M, Sham Y Y, Vince R, Pommier Y and Wang Z 2011 3-Hydroxypyrimidine2,4-diones as an Inhibitor Scaffold of HIV Integrase $J$. Med. Chem. 542282

12. Szmigielski R and Danikiewicz W 2003 NAlkoxymethylation of Secondary Amides, Sulfonamides and Phosphamides Using Dialkoxymethanes in the Presence of Lewis Acids Synlett 372

13. Ledneczki I, Agócs P M and Molnár A 2003 NAlkoxymethylation of Carboxamides Catalyzed by Brønsted Acids Synlett 2255

14. (a) Bal B S and Pinnick H W 1979 Convenient Conversion of Alcohols into Formaldehyde Acetals or Ethers J. Org. Chem. 44 3727; (b) Barot B C and Pinnick H W 1981 Preparation of Formaldehyde and Acetaldehyde Acetals J. Org. Chem. 46 2981; (c) Cornelius A and Lazlo P 1982 Clay-Supported Reagents; II. Quaternary Ammonium-Exchanged Montmorillonite as Catalyst in the Phase-Transfer Preparation of Symmetrical Formaldehyde Acetals Synthesis 162; (d) Deshmukh A R A S, Gumaste V K and Bhawal B M 1995 Montmorillonite, an Efficient Catalyst for the Preparation of 
Dialkoxymethanes Synth. Commun. 25 3939; (e) Pathak D D and Gerald J J 2003 An Efficient and Convenient Method for the Synthesis of Dialkoxymethanes Using Kaolinite as a Catalyst Synth. Commun. 33 1557; (f) Wang, M -L, Hsu S -L and Hsieh Y -M 2006 Synthesis of Dialkoxymethane at High Alkaline Concentration via Phase Transfer Catalysis Chem. Eng. Comm. 193 1368; (g) Aoki H and Mukaiyama T 2006 A Convenient Method for the Synthesis of Dialkyl Ethers by Alkylation of Alcohols Using Phosphinimidates in the Presence of a Catalytic Amount of Trimethylsilyl Triflate Bull. Chem. Soc. Jpn. 79 1255; (h) Yamazaki Y, Kakuma K, Du Y and Saito S 2010 Synthesis of Carbonates Directly from 1 atm $\mathrm{CO}_{2}$ and Alcohols using $\mathrm{CH}_{2} \mathrm{Cl}_{2}$ Tetrahedron 66 9675; (i) Ma Y H, Wu G, Jiang N, Ge S W, Zhou Q and Sun B W 2015 Microwave-Assisted, Facile, Rapid and Solvent-free One Pot Two-Component Synthesis of Some Special Acylals Chin. Chem. Lett. 26 81; (j) Zhan L, Pan R, Xing P and Jiang B 2016 An Efficient Method for the Preparation of Dialkoxymethanes from Dichloromethane with Alcohols Catalyzed by a Cu-NHC Complex Tetrahedron 574036 references cited therein

15. For synthesis of DMM, see: (a) Reuss G, Disteldorf W, Gamer A O and Hilt A 2000 In Ullmann's Encyclopedia of Industrial Chemistry (Weinheim: Wiley-VCH); (b) Hasse H, Drunsel J O, Burger J, Schmidt U, Renner M and Blagov S 2014 Process for the Production of Pure Methylal US20140187823

16. Thenert K, Beydoun K, Wiesenthal J, Leitner W and Klankermayer J 2016 Ruthenium-Catalyzed Synthesis of
Dialkoxymethane Ethers Utilizing Carbon Dioxide and Molecular Hydrogen Angew. Chem. Int. Ed. 5512266

17. (a) Morimoto T and Kakiuchi K 2004 Evolution of Carbonylation Catalysis: No Need for Carbon Monoxide Angew. Chem. Int. Ed. 43 5580; (b) Wu L, Liu Q, Jackstell $\mathrm{R}$ and Beller M 2014 Carbonylations of Alkenes with CO surrogates Angew. Chem. Int. Ed. 53 6310; (c) Gautam P and Bhanage B M 2015 Recent Advances in the Transition Metal Catalyzed Carbonylation of Alkynes, Arenes and Aryl Halides using CO Surrogates Catal. Sci. Technol. 5 4663; (d) Midya S P, Sahoo M K, Landge V G, Rajamohanan P R and Balaraman E 2015 Reversed Reactivity of Anilines with Alkynes in the RhodiumCatalysed C-H activation/Carbonylation Tandem Nature Commun. 6 8591; (e) Sam B, Breit B and Krische M J 2015 Paraformaldehyde and Methanol as $C_{1}$ Feedstocks in Metal-Catalyzed C-C Couplings of $\pi$-unsaturated Reactants: Beyond Hydroformylation Angew. Chem. Int. Ed. 543267

18. (a) Busupalli B, Kummara S, Kumaraswamy G and Prasad B L V 2014 Ultrathin Sheets of Metal or Metal Sulfide from Molecularly Thin Sheets of Metal Thiolates in Solution Chem. Mater. 26 3436; (b) Busupalli B, Date K, Datar S and Prasad B L V 2015 Preparation of $\mathrm{Ni}_{3} \mathrm{~S}_{2}$ and $\mathrm{Ni}_{3} \mathrm{~S}_{2}-\mathrm{Ni}$ nNanosheets via Solution based Processes Cryst. Growth Des. 15 2584

19. Tasker S Z, Standley E A and Jamison T F 2014 Recent Advances in Homogeneous Nickel Catalysis Nature 509 299; and references cited therein. 